\title{
Local and national determinants of household energy consumption in the Netherlands
}

\author{
Bardia Mashhoodi $(\mathbb{D} \cdot$ Dominic Stead $\cdot$ Arjan van Timmeren
}

Published online: 23 January 2019

(C) The Author(s) 2019

\begin{abstract}
The policies of Third National Energy Efficiency Action Plan for the Netherlands, regarding the reduction of household energy consumption (HEC), were made based on the unwritten presumption that the stimuli of HEC are similar in each and every location of the Netherlands, and that it therefore is possible to formulate an identical set of incentives and regulations that are optimally suitable in all the locations of the country. The objective of this study is to examine the validity of this presumption by formulating two research questions: what are the national determinants of HEC, i.e. the stimuli that trigger the same response across the whole country? What are the local determinants of HEC, i.e. the stimuli which trigger different responses across the country? To identify local and national determinants of HEC, the impact of nine determinants of HEC in 2 462 neighbourhoods of the Netherlands is assessed by employing the geographical variability test. The results show that two of the determinants are national: (1) the number of frost-days, (2) wind speed. The results indicate that seven of the determinants are local: (1) income, (2) household size, (3) building age,
\end{abstract}

B. Mashhoodi $(\bowtie) \cdot$ D. Stead · A. van Timmeren Department of Urbanism, Faculty of Architecture and The Built Environment, Delft, The Netherlands e-mail: b.mashhoodi@tudelft.nl

A. van Timmeren

Amsterdam Institute for Advanced Metropolitan

Solutions, Amsterdam, The Netherlands
(4) surface-to-volume ratio, (5) population density, (6) number of summer days, and (7) land surface temperature. By employing a semi-parametric geographically weighted regression analysis, the impact of the local and global determinants of HEC is estimated and mapped.

Keywords Household energy consumption - Semiparametric geographically weighted regression . Mixed geographically weighted regression - Energy policy $\cdot$ Netherlands

\section{Introduction}

The policies of Third National Energy Efficiency Action Plan for the Netherlands (Ministry of Economic Affairs 2014) regarding the reduction of household energy consumption (HEC) were developed based on a one-size-fits-all approach: in the policy document, as it is reported to the European commission, the "geographical area" of all the proposed incentives and regulations is specified as "the Netherlands", without any differentiation according to location-specific circumstances, i.e. socioeconomic patterns, climate, level of urbanisation, land cover, and housing stock (see Table 1). In this respect, the policy is made based on an unwritten presumption: that the stimuli of HEC are similar in 
Table 1 Third National Energy Efficiency Action Plan for the Netherlands (2014) regarding the reduction of residential energy use - all of the listed measures are applicable to the Netherlands as a whole

Policy measure

1. Tightening of energy performance standards (EPC) of buildings

2. Lente Agreement on energy-efficient new buildings

3. More with Less: agreement for energy saving in existing residential and other buildings

4. Changes to the Home Valuation System: link maximum rent of a dwelling to its energy label

5. Reduced VAT rate for the maintenance and renovation of residential buildings

6. Block-by-block approach (large-scale approach to improve existing housing stock)

7. Acceleration (facilitating investments in improving the energy efficiency of residential buildings)

8. Revolving fund for energy saving (encouraging investment in the energy efficiency of existing buildings)

9. Energy-saving agreement for the rental sector (corporations, landlords, tenants)

10. Subsidy available for landlords in the social rental sector to improve the energy efficiency of buildings

11. Energy tax (tax levy on energy tariffs)

12. EIA: Energy Investment Allowance (tax reduction for the purchase of energy-efficient equipment)

13. Green Investment and Finance (tax incentive for investment in environmental friendly projects)

14. Green Deal (support for investment in energy-saving and renewable energy measures)

each and every location of the Netherlands, and that it therefore is possible to formulate an identical set of incentives and regulations that is optimally suitable in all locations of the country. This presumption is not valid. The presumption, however, reflects a gap in the existing body of literature on HEC. Almost all the previous studies are based on the assumption that the determinants of HEC are identical across all areas, and almost all have tried to discover the universally applicable rules that explain the level of HEC. A small portion of previous studies, in contrast, has presumed that all determinants of HEC are locationspecific. These studies, however, have failed to prove whether or not that is the case for each and every determinant of HEC.

The objective of this study is bridge the knowledge gap by seeking answers to two research questions: what are the national determinants of HEC, i.e. the stimuli that trigger the same response across the whole country? What are the local determinants, i.e. the stimuli that trigger different responses across the country? This study analyses annual energy consumption per capita within dwellings (HEC) in the neighbourhood units - a rough translation of the Dutch wijk —of the Netherlands in 2014. The level of HEC is studied against nine independent variables that have previously been considered effective determinants of
HEC: income, household size, building age, surfaceto-volume ratio of buildings, population density, degree days (i.e. number of summer days and number of frost days), wind speed, and land surface temperature. The methodology of this study is twofold. First, by employing the geographical variability test (Nakaya et al. 2009), the local and national determinants of HEC are identified. Second, by employing a semi-parametric geographically weighted regression (SGWR) analysis, the impact of national and local determinants of HEC is estimated and mapped. In the next parts, the previous studies are briefly reviewed, and the methodology and data of this study are described. Results and conclusions are presented at the end.

\section{Previous studies on local and global determinants of household energy consumption}

Subsequent to the publication of the two seminal papers on modelling spatial associations (Brunsdon et al. 1996; Fotheringham et al. 1996), and the followup book by Fotheringham et al. (2003), two new concepts went viral among scholars conducting geographic analysis: (1) local determinants, i.e. the insight that the impact of a phenomenon is spatially non- 
stationary and thus varies from one location to another; (2) global determinants, i.e. the stimuli of a phenomena that provoke the same response in all locations of interest. This new perspective sharply contrasted with the presumption that underlies studies prior to that date-which merely searched for global explanations for different spatial phenomena-and left a profound impact on the studies in different fields; scholars in different disciplines have disclosed the local determinants of a variety of geographic phenomena, e.g. violent crime (Stein et al. 2016), regional development (Yu 2014), poverty (Vaziri et al. 2018), residential burglary (Zhang and Song 2014), and utilisation of prenatal care (Shoff et al. 2012). It has also raised a new and fundamental question for scholars in different disciplines: what are the local and global determinants of the phenomenon in question? A variety of studies have shown that the best understanding of a range of phenomena-e.g. hedonic house price (Geniaux and Napoléone 2008), academic performance (Figueroa et al. 2018), soil organic matter (Zeng et al. 2016) — is achieved only when global and local determinants are distinguished.

In the last two decades, while the local and global determinants of the phenomena of interest have been explored in a variety of disciplines, HEC studies have significantly lagged behind in the application of the new methods of geographic analysis. Previous empirical studies on HEC could be categorised into two groups according to their methodology. The first group, accounting for the vast majority of previous studies on HEC, neglects the possibility that determinants of HEC could be local. These studies are based on an underlying presumption that all determinants of HEC are global, i.e. they presume that there are some generic rules applicable to all locations. A variety of the studies following this presumption have cited global rules to explain levels of HEC, such as the following examples: the higher the income level, the higher the HEC (Druckman and Jackson 2008; Joyeux and Ripple 2007); per capita HEC drops in larger households (Kowsari and Zerriffi 2011; Isaac and Van Vuuren 2009); the older a building, the higher the HEC (Belaiid 2016; Steemers and Yun 2009); the higher the surface-tovolume ratio of the buildings, the higher the HEC (Steemers and Yun 2009; Druckman and Jackson 2008); HEC drops in areas with a higher population density (Porse et al. 2016; Pachauri and Jiang 2008); the more cooling and heating degree days there are, the higher the level of consumption (Wiedenhofer et al. 2013; Reinders et al. 2003); the impact of windspeed on the heat loss of buildings is substantial enough to change the level of HEC (Sanaieian et al. 2014; van Moeseke et al. 2005); land surface temperature affects HEC in all urban areas (Azevedo et al. 2016; Lee and Lee 2014).

The second group of the earlier studies is based on the underlying assumption that all determinants of HEC are local. Bouzarovski and Simcock (2017, p. 640) state that "there are clear geographic patternings associated with [household] energy [consumption and] poverty, as well as a geographically embedded and contingent nature of ... underlying causes." $\mathrm{Yu}$ (2012) concludes that in eastern China, the intensity of energy use of a province is strongly associated with that of its neighbouring provinces, and that there is a "convergence [between] provincial energy intensity." (2012, p. 583). Robinson et al. have observed that "vulnerabilities [to energy poverty] associated with disability or illness ... is stronger ... in some southern cities [of England] including London, Luton and Southampton." (2018, pp. 12-13). An analysis of the carbon emissions related to HEC in north-west China conclude that the determinants of pollution vary from one region to another: "income indicates a greater influence," for instance, "in northern Ningxia and northern Shaanxi" (Li et al. 2016, p. 183). A study on HEC in California (Sultana et al. 2018) estimated that the aging of the population has a significant impact on increasing HEC in north-eastern areas, whereas no significant effect is expected in the north-western areas. Two studies on HEC in the Randstad region in the Netherlands show that building age, as a proxy for buildings' energy efficiency, has a greater impact in rural areas than in urban areas (Mashhoodi 2018), and the main determinant of households' gas consumption-i.e. building age, household size, income, and population density - vary across neighbourhoods of the region (Mashhoodi and van Timmeren 2018).

There is a knowledge gap in the previous studies on HEC. Most of the earlier studies presumed that the determinants of HEC are global, while some studies presumed that all determinants of HEC are local. A central and fundamental question, however, has never been posed: what are the local and global determinants of HEC? 


\section{Methodology}

This study aims at estimating the local and global determinants of HEC. In the first step of the analysis, a convectional linear regression model, OLS, which holds all the determinants as global determinants of HEC, is employed:

$y_{i}=\beta_{0}+\sum_{k} \beta_{k} x_{i k}+\varepsilon_{i}$

where $y_{i}$ denotes the estimated value of HEC in the location $i, \beta_{0}$ denotes the intercept, and $\beta_{k}$ shows the coefficient slope of the $k$ th independent variable. $x_{i k}$ and $\varepsilon_{i}$ show the values of independent variables and random error term in location $i$. In the second step of the analysis, the GWR model, all the independent variables are held as local determinants of HEC:

$y_{i}=\beta_{0}\left(\mu_{i}, v_{i}\right)+\sum_{k} \beta_{k}\left(\mu_{i}, v_{i}\right) x_{i k}+\varepsilon_{i}$

where $\left(\mu_{i}, v_{i}\right)$ shows the $\mathrm{x}-\mathrm{y}$ coordinate of location $i$. $\beta_{k}\left(\mu_{i}, v_{i}\right)$ and $\beta_{0}\left(\mu_{i}, v_{i}\right)$ are the local coefficient and intercept of $k$ th independent variable in location $i$. A fixed Gaussian function is used to weight the instances around location $i$ :

$W_{i j}=\left\{\begin{array}{l}\exp \left(-d_{i j}^{2} / \theta_{i(k)}^{2}\right), \quad \text { if } d_{i j}<\theta \\ 0, \quad \text { otherwise }\end{array}\right.$

where $W_{i j}$ is the weight assigned to the instance observed at location $j$ for the estimation of local coefficients at location $i, d_{i j}$ is the geodesic distance between $i$ and $j$ in metres, and $\theta_{i(k)}$ is the fixed bandwidth. Using the golden selection function of the GWR 4.0 tool (Nakaya et al. 2009), the optimal $\theta_{i(k)}$, which minimises the AICc (Akaike information criterion) value of the GWR model, is determined. To identify local and national determinants of HEC, for each of the $k$ independent variables in Eq. 2, a geographical variability test is applied. The third session, a semi-parametric geographically weighted regression, SGWR, estimates the effect of global and local determinants of HEC:

$y_{i}=\beta_{0}\left(\mu_{i}, v_{i}\right)+\sum_{m} \beta_{m}\left(\mu_{i}, v_{i}\right) x_{i m}+\sum_{n} \gamma_{n} z_{n i}+\varepsilon_{i}$

where $\beta_{m}\left(\mu_{i}, v_{i}\right)$ denotes the coefficient of the $m$ th local determinant at location $i$, and $\gamma_{n}$ shows the coefficient of the $n$th national determinant. A fixed Gaussian function is used. The optimal bandwidth for the SGWR model is estimated by the golden selection function of GWR 4.0.

The performance of the OLS, GWR, and SGWR models is compared by means of four tests: adjusted $\mathrm{R}^{2}$, AICc (corrected Akaike information criterion), cross-validation (CV), and randomness of the spatial distribution of the residuals (assessed by Moran's I).

\section{Data and case study}

Case study

The case study of this research is comprised of the neighbourhood units, wijken in Dutch, of the Netherlands. The neighbourhoods are spatial divisions defined by the Dutch central bureau of statistics (CBS). The CBS divides all areas of the Netherlands into 2836 neighbourhood units. The reason for the use of the neighbourhood units is the availability of data: the CBS annually publishes data on a variety of socioeconomic characteristics of the neighbourhoods. This study is carried out on 2462 out of the 2836 neighbourhoods of Netherlands. The neighbourhoods excluded from the study, accounting for $15 \%$ of the total, are of six types: (1) water bodies; (2) the neighbourhoods that are not covered by the satellite image of 17 September 2014 (which is used to calculate land surface temperature); (3) the neighbourhoods covered by cloud in the satellite image; (4) the neighbourhoods of the three isolated islands of Texel, Terschelling and Nes; (5) non-residential neighbourhoods; (6) neighbourhoods identified as an outlier based on an abnormally low level of HEC per capita. The reason for excluding the latter is that the CBS database on households' gas and electricity consumption merely reports the consumption supplied from the distribution grid of gas and electricity in the neighbourhoods. The supply from district-heating systems or solar panels, however, is not reported by the CBS database. It is likely that a neighbourhood with an abnormally low level of consumption in the CBS database is provided with district-heating or a large number of solar panels. In this case, the neighbourhoods with an abnormally low values (zscore $<2.5$ ) are excluded from this study (Fig. 1). 


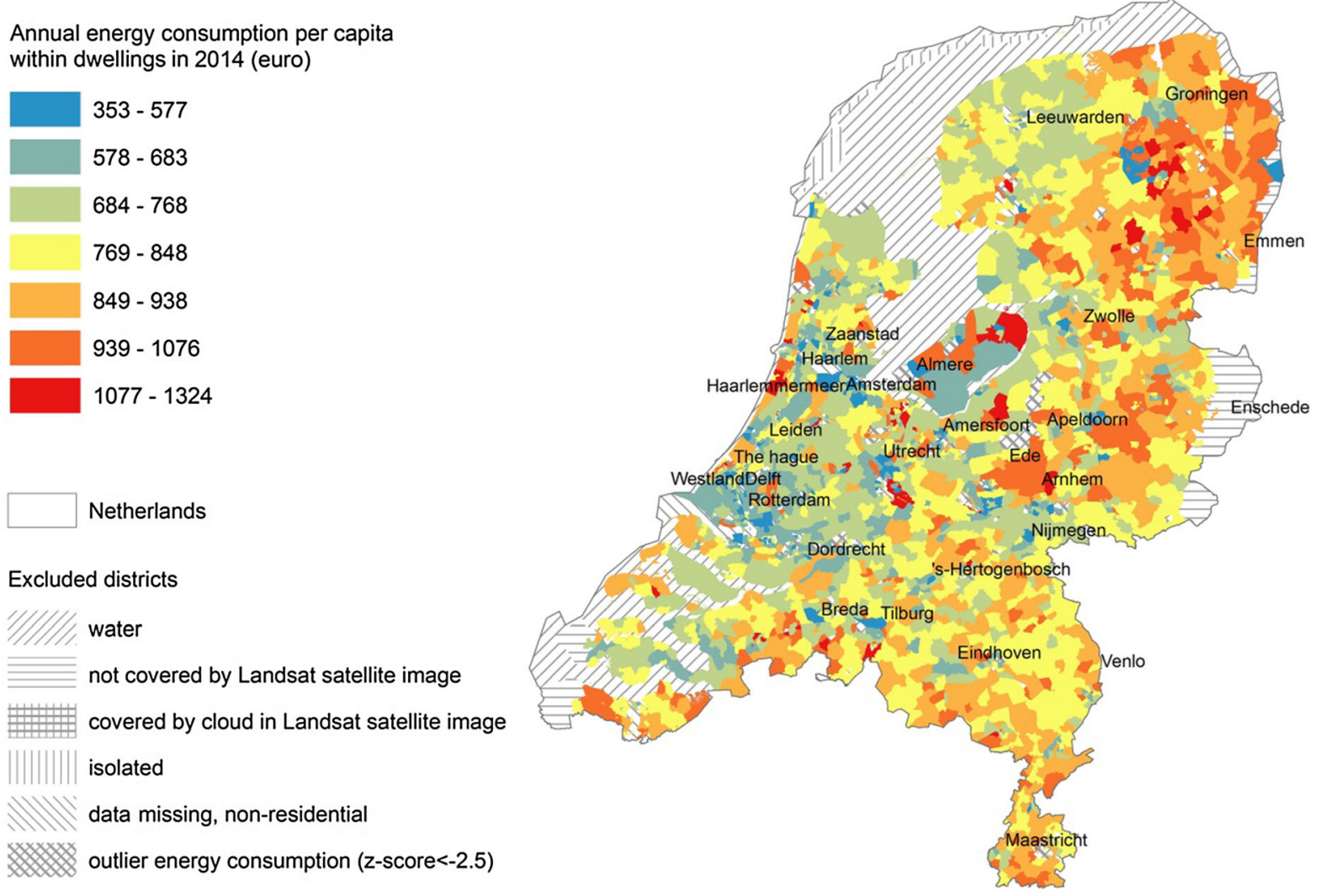

Fig. 1 Case study and dependent variables of the study

Dependent variable

The dependent variable of this study is annual expenditure per capita, on gas and electricity, within dwellings in 2014 (Fig. 1). The data on gas and electricity is provided by the CBS (Centraal Bureau voor de Statistiek 2013). The average gas and electricity price for domestic use in the Netherlands, in 2014, is provided by Eurostat (2015).

Independent variables

This study is conducted on nine independent variables (see Table 2). Income shows annual disposable income per capita. Household size shows the average household size in the neighbourhoods in question. Building age shows the median age of the buildings. Surface-to-volume shows the ratio of buildings' external surfaces to their volume. Population density denotes the number of inhabitants per square kilometre. Following the definitions of degree days provided by the Royal Netherlands Meteorological Institute (KNMI), the air temperature in neighbourhoods is measured by two variables: Summer days, the number of days with a maximum temperature higher than 25 degrees Celsius, and Frost days, the number of days with a minimum temperature lower than 0 degrees Celsius. To obtained the variables, based on KNMI guidelines (Sluiter 2012), the number of summer days and frost days in the KNMI's 28 meteorological stations is interpolated-universal kriging with external drift of log distance to shore.

Wind-speed shows the speed of the wind blowing at a height of $10 \mathrm{~m}$ above ground. The variable is obtained based on a two layer model of the planetary boundary layer (for a detailed description see Stepek and Wijnant 2011). To conduct the calculations three datasets are used: wind speed at KNMI meteorological stations in 2014 (KNMI 2018); the CORINE landcover database (European Environment Agency 2016) and the roughness length classifications of the CORINE land-cover classes (Silva et al. 2007); and 
Table 2 Descriptive statistics of the independent variables

\begin{tabular}{lcllc}
\hline Variable & Mean & Minimum & Maximum & SD \\
\hline Income & 23.11 & 12.00 & 52.70 & 3.80 \\
Household size & 2.35 & 1.24 & 4.00 & 0.30 \\
Building age & 39.33 & 0 & 164 & 15.01 \\
Surface-to-volume & 0.2691 & 0.1128 & 0.3972 & 0.0347 \\
Population density & 1777.66 & 3 & 21,656 & 2591.81 \\
Summer days & 23.1080 & 6.0600 & 37.6800 & 8.0470 \\
Frost days & 68.8040 & 52.6200 & 80.7400 & 6.3187 \\
LST & 21.75 & 15.23 & 26.22 & 1.03 \\
Wind speed & 39.58 & 28.39 & 64.63 & 5.28 \\
\hline
\end{tabular}

finally the land surface temperature (LST) on 17 September 2014. The variable is used as a proxy for the average LST in different seasons. The choice of the date was due to two facts. First, there are few days in which the Landsat- 8 satellite image of the Netherlands is available and a large part of the country the areas is not covered by cloud. Secondly, most of the vegetation and trees are green in September, therefore miscalculation of the NDVI (Normalized Difference Vegetation Index), which is used as the basis for calculating LST, could be avoided. To obtain LST, the atmosphere spectral radiance is first calculated:

$L_{\lambda}=M_{L} Q_{c a l}+A_{L}$

where $L_{\lambda}$ is the top of the atmosphere spectral radiance, $M_{L}$ is the band 10 multiplicative rescaling factor from metadata (3.3420E-04), $Q_{\text {cal }}$ is the band 10 value in the Landsat- 8 image, and $A_{L}$ is the band 10 additive rescaling factor from metadata (0.1). Subsequently the satellite brightness temperature is calculated:

$T=K_{2} /\left(\ln \left(K_{1} / L_{\lambda}+1\right)\right)$

where $T$ is the satellite brightness temperature and $K_{2}$ (1321.08) and $K_{1}(774.89)$ are thermal conversion constants for band 10 . To correct $T$ for land-cover emissivity, the emissivity-corrected surface temperature, LST, is corrected as follows:

$$
\begin{aligned}
& L S T=T /\left(1+\left(\frac{\lambda T}{\rho}\right) \cdot \ln (\varepsilon)\right) \\
& \varepsilon=0.004 P_{V}+0.986
\end{aligned}
$$

$P_{V}=\left(\frac{N D V I-N D V I_{\min }}{N D V I_{\max }-N D V I_{\min }}\right)^{2}$

$N D V I=\frac{N I R-R e d}{N I R+R e d}$

where LST is the emissivity-corrected surface temperature, $\lambda$ is the wavelength of emitted radiance (11.5), $\varepsilon$ is emissivity, $P_{V}$ is vegetation proportion, NIR is near infrared (band 5), and Red is band 4 in the Landsat-8 image (USGS 2018a; Stathopoulou and Cartalis 2007; Kim 2013).

The data on Income, Household size and Population density are provided by the Wijk-en-buurt-kaart 2014 (Centraal Bureau voor de Statistiek 2013). The data used to calculate Building age and Surface-to-volume are obtained by use of the building height database3D BAG (Esri Netherlands 2016). Data of meteorological stations-used to calculate Summer days, Frost days and Wind speed-are provided by Royal Netherlands Meteorological Institute (KNMI 2018). Data on land-cover-used to calculate surface roughness length to obtain Wind speed - is provided by the CORINE database (European Environment Agency 2016). The Landsat- 8 satellite images-used to calculate LST-is taken from the USGS website (USGS 2018b).

\section{Results}

The identification of local and national determinants of HEC

The geographical variability test, formulated by Nakaya et al. (2009), is used for the identification of 
local and national determinants. The test is based on a comparison between performance of multiple GWR models. To assess geographical variability of the $k$ th independent variable a model comparison between two models is carried out: first, a GWR model which holds all variables as local and the $k$ th variable as national; second, a GWR model which holds all the variables as a local variable. A comparison between $\mathrm{AICc}$ of the two models determines whether the $k$ th variables are local or national determinants of HEC: if the AIC of the second model is lower than that of the first model, the "DIFF of Criterion" measure is smaller than zero, then the $k$ th variable is a local determinant of HEC; if not, the $k$ th is a national determinant. The application of the geographical variability test shows that two of the variables are national: Frost days, and Wind speed. The results indicate that seven of determinants are local: Income, Household size, Building age, Surface-to-volume, Population density, Summer days, and LST (Table 3).

In order to check for multicollinearity between the nine determinants, an OLS model is applied. The results show that the Variance Inflation Factor (VIF) of all the independent variables is well below the maximum threshold of 2.5. This implies that the effect of the variables is fairly unique and therefore there is no multicollinearity bias (Table 3 ).
Comparison between the performance of the SGWR model and that of the GWR and OLS models

Subsequent to the identification of the local and global determinants of HEC, a SGWR model is employed. The model estimates the impact of the determinants of HEC by simultaneously holding two of the variables as global determinants and seven of the variables as local determinates (Table 4).

The comparison between the performance of the SGWR model and that of the OLS model (which holds all variables as global determinants) and the GWR model (which holds all variables as local determinants), shows that the former model provides the best understanding of HEC in the neighbourhoods of the Netherlands: the SGWR model has the lowest level of AIC, AICc and CV, the highest value of the adjusted R-square, and the most random spatial distribution of residuals—assessed by Moran's Index (Table 5).

Estimates of the local and national determinants of HEC

The results of the SGWR model show that the estimated coefficient of one of the two national determinants, Frost days, is significant at the $p$ value $<0.01$ level. The coefficient is larger than the estimated effect of the local determinants of HEC

Table 3 Geographical variability test and estimates of OLS and GWR models

\begin{tabular}{|c|c|c|c|c|c|c|c|c|}
\hline \multirow[t]{2}{*}{ Variable } & \multicolumn{2}{|l|}{ OLS results } & \multicolumn{4}{|c|}{ GWR results } & \multicolumn{2}{|c|}{ Geographical variability test } \\
\hline & $\beta$ & VIF & $\beta$ mean & $\beta$ min & $\beta \max$ & $\beta \mathrm{SD}$ & DIFF of criterion & Determinant type \\
\hline Intercept & $0.000 * *$ & & 0.032 & -17.568 & 15.424 & 2.315 & -1078.42 & \\
\hline Income & $0.271 * *$ & 1.1 & 0.406 & -0.958 & 0.839 & 0.129 & -16.96 & Local \\
\hline Household size & $-0.098 * *$ & 1.63 & -0.042 & -0.795 & 0.555 & 0.205 & -60 & Local \\
\hline Building age & $0.340 * *$ & 1.36 & 0.336 & 0.019 & 0.761 & 0.125 & -18.79 & Local \\
\hline Surface-to-volume & $0.061 * *$ & 1.34 & -0.015 & -0.277 & 0.256 & 0.101 & -8.62 & Local \\
\hline Population density & $-0.532 * *$ & 1.76 & -0.528 & -1.271 & -0.027 & 0.216 & -48.36 & Local \\
\hline Summer days & $0.043^{*}$ & 1.81 & 0.53 & -11.497 & 11.805 & 1.668 & -97.16 & Local \\
\hline Frost days & $0.173 * *$ & 1.78 & -0.184 & -5.603 & 4.36 & 1.001 & 3.84 & National \\
\hline Wind speed & 0.003 & 1.14 & -0.016 & -0.515 & 0.184 & 0.059 & 42.79 & National \\
\hline LST & $-0.097 * *$ & 2.06 & -0.058 & -0.435 & 0.547 & 0.152 & -11.89 & Local \\
\hline
\end{tabular}

$\beta$ standardized regression coefficient

$* p$ value $<0.05 ; * * p$ value $<0.01$ 
Table 4 Estimates of the SGWR model

$\beta$ standardized regression coefficient

$* * p$ value $<0.01$

\begin{tabular}{|c|c|c|c|c|c|c|}
\hline \multirow[t]{2}{*}{ Variable } & \multicolumn{2}{|c|}{ National coefficients } & \multicolumn{4}{|c|}{ Local coefficients } \\
\hline & $\beta$ & SE & $\beta$ mean & $\beta \min$ & $\beta \max$ & $\beta \mathrm{SD}$ \\
\hline Intercept & & & -0.451 & -13.240 & 3.247 & 0.995 \\
\hline Income & & & 0.410 & -0.803 & 0.946 & 0.155 \\
\hline Household size & & & -0.047 & -0.969 & 0.729 & 0.217 \\
\hline Building age & & & 0.336 & -0.038 & 0.906 & 0.138 \\
\hline Surface-to-volume & & & -0.011 & -0.389 & 0.293 & 0.113 \\
\hline Population density & & & -0.547 & -1.605 & -0.016 & 0.255 \\
\hline Summer days & & & -0.316 & -7.809 & 2.236 & 0.688 \\
\hline Frost days & $0.623 * *$ & 0.170 & & & & \\
\hline Wind speed & -0.017 & 0.014 & & & & \\
\hline LST & & & -0.048 & -0.567 & 0.618 & 0.175 \\
\hline
\end{tabular}

Table 5 Diagnostics of the OLS, GWR and SGWR models

\begin{tabular}{llcc}
\hline & OLS & \multicolumn{1}{l}{ GWR } & \multicolumn{1}{l}{ SGWR } \\
\hline AIC & 5394.08 & 4711.53 & 4645.60 \\
AICc & 5394.19 & 4788.57 & 4733.63 \\
CV & 0.5251 & 0.4349 & 0.4311 \\
R $^{2}$ & 0.481 & 0.686 & 0.699 \\
Adjusted R $^{2}$ & 0.479 & 0.626 & 0.638 \\
Residuals Moran's I & 0.1718 & 0.0211 & 0.0163 \\
Bandwidth (m) & NA & $12,867.58$ & $11,070.30$ \\
\hline
\end{tabular}

in almost all neighbourhoods of the Netherlands. This result implies that the number of frost days is the most influential determinant of HEC, and this statement could be generalised for all neighbourhoods. The estimated coefficient of the other national determinant, Wind speed, is not significant at the $p$ value $<0.05$ level. Wind speed, therefore, is not an effective factor of HEC in the neighbourhoods of the country. In the case of the estimated local coefficients, it is found that, Income and Building age have a substantial impact on increasing HEC levels. Population density has a considerable impact on decreasing the HEC levels of most neighbourhoods. In the case of Summer days, LST and Household size, the local impact of the determinate could vary in nature across the neighbourhoods, i.e. in some neighbourhoods they contribute to mitigate levels of HEC, whereas in others they boost the levels of HEC (Fig. 2).

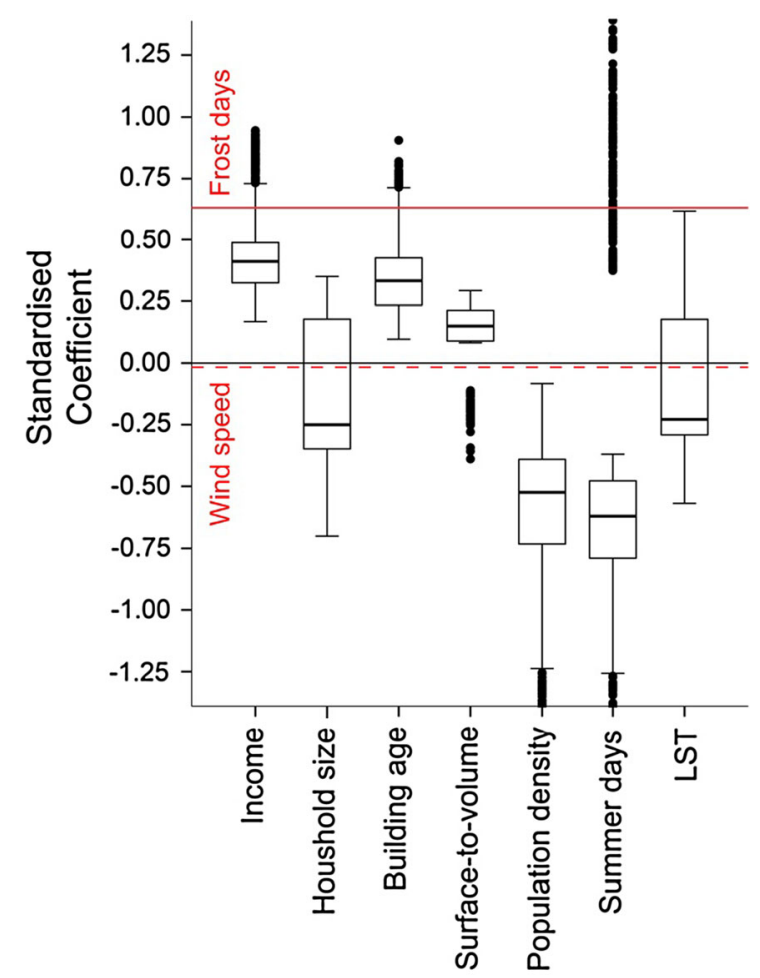

Fig. 2 The box plot illustrates the variability of the coefficients of local determinants of HEC. The solid red line shows the coefficient of the significant national determinant (Frost days). The dashed red line shows that of the not-significant national determinant (wind speed). (Color figure online)

The distribution of local coefficients across the neighbourhoods of the Netherlands shows that more than $93 \%$ of the local coefficients of Income are significant at the $p$ value $<0.05$ level, which are all positively associated with HEC. A pocket of high 
values is observed in the north-east of the country between the cities of Groningen, Emmen, Zwolle and Leeuwarden (Fig. 3a).

Some $37 \%$ of the local coefficients of Household size are significant at the $p$ value $<0.05$ level. The sign of almost $71 \%$ of the significant coefficients is negative, where that of $29 \%$ is positive. Most of the negative coefficients are observed in the areas of The Hague, Rotterdam and the area north and west of Amsterdam, i.e. Haarlem and Zaanstad. The largest positive coefficients are observed in vicinity of Tilburg and Breda. Also, in some neighbourhoods Amsterdam and Utrecht a modest positive coefficient is observed (Fig. 3b).

In the majority (89\%) of neighbourhoods, the local coefficient of Building age is significant at the $p$ value $<0.05$ level, which is positively associated with HEC. The magnitude of the association is remarkably lower in the case of the most urbanised part of Netherlands, the so-called Randstad, comprised of the four main Dutch cities of Amsterdam, Utrecht, Rotterdam and The Hague (Fig. 3c).

In merely $13 \%$ of the neighbourhoods the local coefficient of Surface-to-volume is significant at the $p$ value $<0.05$ level. The majority of the significant coefficients, nearly $78 \%$, are positive. The largest pockets of positive values are observed in the areas enclaved between the Markermeer lake and the North sea, as well as on the banks of the river Nieuwe Maas. The areas with negative local coefficients are dispersed (Fig. 3d). In a majority of the neighbourhoods, nearly 91\%, coefficients of Population density are significant at the $p$ value $<0.05$ level, which is associated with lower levels of HEC. The magnitude of the effect is lower in the more urbanised areaeminently the Randstad (Fig. 3e).

In the case of Summer days, almost in $39 \%$ of the neighbourhoods local coefficients are significant ( $p$ value $<0.05$ ). Distribution of the coefficient value shows a clear geographical pattern: there is a gradual change from largest negative coefficients in the north-

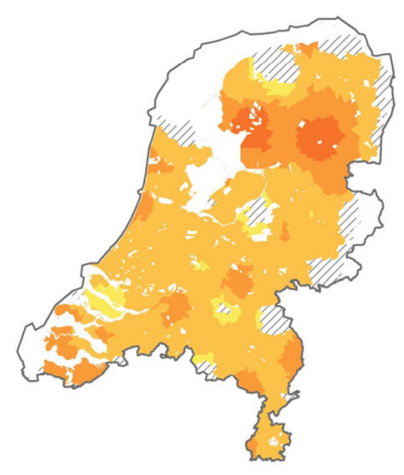

(a) Income

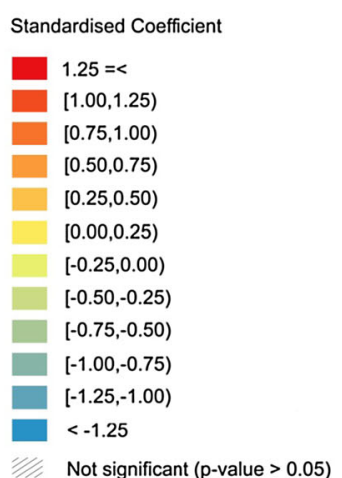

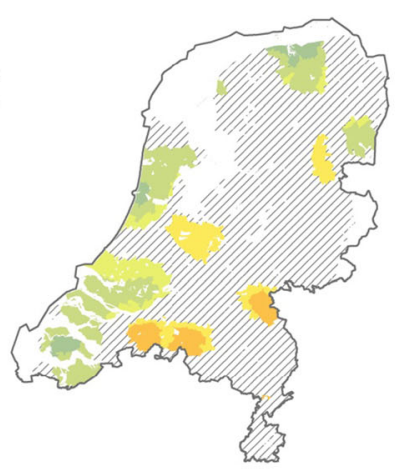

(b) Household size

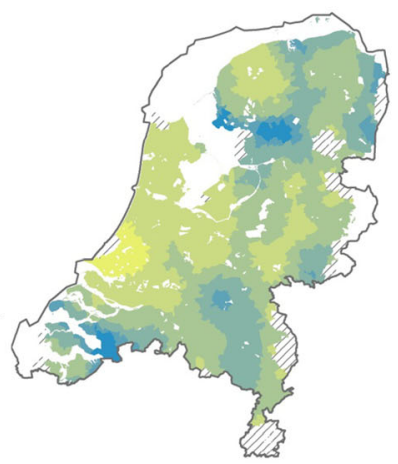

(e) Population density

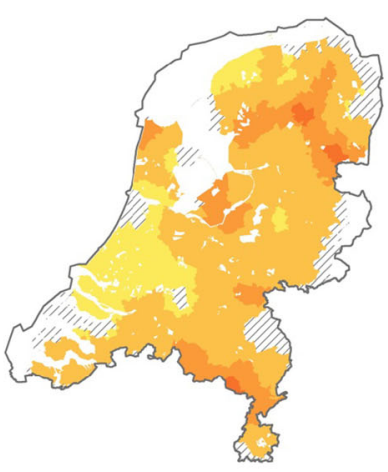

(c) Building age

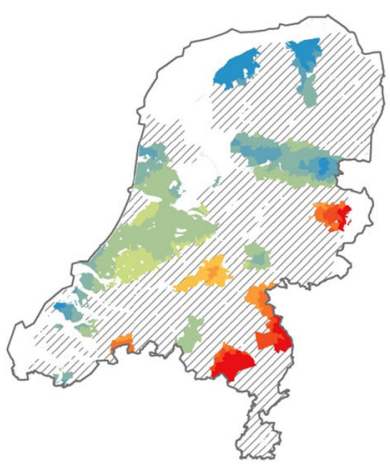

(f) Summer days

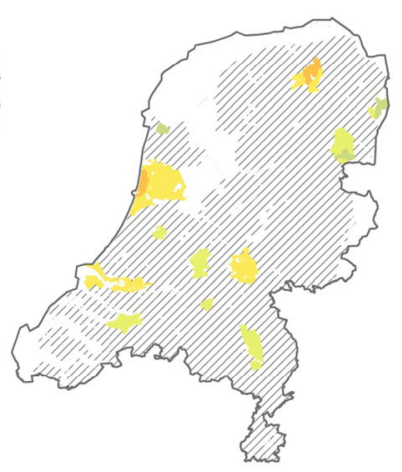

(d) Surface-to-volume

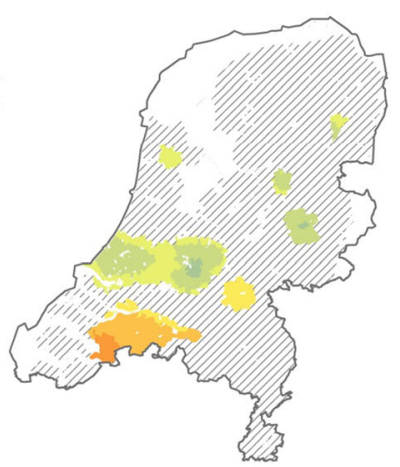

(g) Land Surface Temperature (LST)

Fig. 3 Spatial variation of the estimated standardised coefficients of the local determinants of HEC 
west to large positive coefficients in the south-east. Almost $84 \%$ of the significant coefficients are negative (Fig. 3f). Some $26 \%$ of the local coefficients of $L S T$ are significant at the $p$ value $<0.05$ level. Most of the negative coefficient values are concentrated in the vicinity of Westland, The Hague, Rotterdam and south of Utrecht. About one fourth of the positive local coefficients are located in the vicinity of Tilburg and Breda (Fig. 3g).

\section{Discussion}

The results show that most of the determinants of HEC are local, i.e. their impact varies across the neighbourhoods of the country. Merely two of the nine determinants of HEC are identified as national determinants: Frost days and Wind speed. The results show that the impact of merely one of the national determinants, Frost days, is statistically significant. The impact is remarkably large; in most of the neighbourhoods, Frost days is the most decisive determinant of HEC. This national-scale impact could be explained by the substantial share of heating-related consumption of total HEC in the Netherlands. The data on enduse of energy in the Netherlands published by Eurostat shows that $63 \%$ of total energy consumed by the households is related to space heating and nearly $17 \%$ is related to water heating (Eurostat 2018). In short, there is just one national-scale explanation for HEC in all neighbourhoods of Netherlands: the higher the number of frost days, the higher the level of HEC. The impact of the rest of the determinants of HEC, however, is highly variable across the neighbourhoods of the Netherlands. In the next paragraphs the local determinants of HEC and their spatial variability across the country are discussed.

The results reveal a strong association between levels of Income and HEC. The strongest association is observed in the north-east of the country. Given that the neighbourhoods in the north-east of the country are among the most energy intensive neighbourhoods of the Netherlands, presumably the associations between Income and HEC increases at the upper end of the consumption spectrum. This could be explained from a behavioural point of view: the life-style of a heavy user is constructed such that (s)he increases the level of consumption if and when it is affordable to do so (similar to conclusions drawn by Kaza 2010).
The results show that Household size could have an opposite impact on the HEC of different neighbourhoods. In most of the neighbourhoods, a larger Household size is associated with lower levels of HEC. This is in line with the conclusions drawn by a variety of previous studies (e.g. O'Neill and Chen 2002) which explain a similar observation by referring to economies of scale in large households. Unexpected results are observed in some neighbourhoods of Amsterdam and Utrecht where larger Household size is found to be associated with higher levels of HEC. This is presumably due to higher HEC per capita in households with young children compares to young single-person-households. Amsterdam and Utrecht are cities with a relatively large young population and known for their lively urban life. A large portion of small households accounts for young people who are less bounded to indoor activities, do not parent children, and possess a smaller number of appliances. The HEC in such a household could be significantly lower than in a larger household with young children in which energy consumption for cooking and water heating is higher (Weber and Perrels 2000); the motivation for energy saving is lower (Abrahamse and Steg 2009; Barr et al. 2005); and the possession of a variety of appliances is more common.

The results show that a higher Building age, as a proxy for buildings' energy inefficiency, is associated with higher levels of HEC. This is no unexpected discovery. However, what is special to the results of this study is that this association is weaker in the more urbanised areas, specifically in the Randstad region. In other words, the more urbanised the areas, the less important the energy efficiency of the buildings. This result opens a new dimension for studies focused on the relation between urbanisation and energy consumption. A variety of previous studies have examined the effect of urbanisation on the total amount of energy consumption (e.g. Wang 2014); however possible changes to the determinants of HEC in response to the level of urbanisation has barely been studied.

In most of the neighbourhoods no significant association between HEC and Surface-to-volume is found. In the areas with a scattered pattern of urbanisation and exposure to the sea breeze from the North Sea, Surface-to-volume is found to be associated with a higher level of HEC. As suggested by various previous studies, presumably this is due to higher heat 
loss of the dwellings. Higher Surface-to-volume has an opposite impact on HEC of some neighbourhoods in the east and south of the Netherlands. In the latter a higher surface-to-volume is associated with lower levels of energy consumption. Considering the warmer weather in these areas, presumably a larger building surface decreases the energy used for ventilation.

The results show that, in almost all areas of the Netherlands, a higher Population density is associated with lower levels of HEC. The association is remarkably higher in less urbanised areas, e.g. the neighbourhoods located in the south of Friesland and Zeeland provinces. Presumably, this is due to a marked difference between the life-styles of residents of more urbanised neighbourhoods and to those in adjacent rural neighbourhoods: urbanites tend to be more engaged in outdoor activities and spend less time at home; this can result in a substantial decrease in levels of HEC (similar to the conclusions drawn by Heinonen et al. 2013; Yu et al. 2013).

The number of Summer days could have a different impact in different neighbourhoods. In the neighbourhoods toward the north-west, where Summer days are less frequent, an increase in the number of Summer days is associated with lower HEC. This is presumably due to less energy consumed for water heating and more outdoor activities. In contrast, in the south-east, with more frequent heat waves in summer, the factor is associated with higher HEC. Presumably, the increase in the number of Summer days boosts electricity consumption for space cooling in these neighbourhoods.

In areas in the vicinity of Rotterdam, the Hague and Utrecht, higher values of $L S T$ are associated with lower levels of HEC. Higher levels of LST could result in an increase in air temperature. Presumably, this contributes to a decreased amount of energy consumed for space heating in these areas. An opposite association is observed in some southern neighbourhoodswith a warmer climate-where higher levels of $L S T$ is associated with higher HEC. Presumably, the higher air temperature consequent to higher levels of LST results in higher energy consumption for spacecooling in these neighbourhoods (similar to what is suggested by Lee and Lee 2014; Ewing and Rong 2008).

\section{Conclusion and policy implications}

The core objective of this study was to examine the validity of an unwritten presumption underlying the policies regarding HEC in the Netherlands: that the stimuli of HEC are similar in each and every location of the Netherlands, and that it is therefore possible to formulate an identical set of incentives and regulations that is optimally suitable in all locations of the country. The results show that the validity of such a presumption is questionable. It is established that the determinants of HEC in the Netherlands could be categorised in two types: national determinants and local determinants. The effect of national determinants (Frost days and Wind speed) on HEC could be generalised across all the neighbourhoods of the country, whereas the effect of local determinants (Income, Household size, Building age, Surface-to-volume, Population density, Summer days, and LST) vary from one neighbourhood to another. In this case the most effective way to reduce HEC could be related to a variety of factors that could vary from one neighbourhood to another. These findings have two major policy implications: first, one-size-fits-all policies need to be completed with location-specific strategies; secondly, in order to properly address the local determinants of HEC, the policies need to be enriched by the addition of socioeconomic, morphological and climate-related angles to their approach. The two policy implications are elaborated in the next paragraphs.

It is established that the nature and magnitude of local determinants' impact vary across the neighbourhoods of the Netherlands. In the most eminent cases, an increase in Household size and Summer days can have an opposite impact on the HEC of different neighbourhoods. In the case of other local determinants, though the nature of the effect is similar in all the neighbourhoods, their magnitude differs vastly from one neighbourhood to another. For instance, though it is established that a higher Building age, as a proxy for buildings' energy efficiency, is associated with higher levels of HEC, such an effect is substantially smaller in highly-urbanised neighbourhoods. In this respect, a rigid set of policies would not optimally suit the different local circumstances in various parts of the country. As the energy efficiency of buildings is more crucial in less urbanised areas, for instance, building regulations could be tightened up in suburban 
and rural neighbourhoods, and additional incentives for building renovation could be introduced.

Most of the incentives and regulations introduced by the policies are related to buildings' energy efficiency. The results of this study, however, show that energy consumption within dwellings is affected by a variety of factors such as income, household type, urban morphology, population density and urbanisation, land surface temperature and urban heat islands. It is established that in some neighbourhoods the effect of such factors outnumbers that of buildings' energy efficiency. Presumably, this is the reason that the actual energy consumption of the labelled dwellings in the Netherlands does not necessarily match to their theoretical energy consumption (Majcen et al. 2013). This calls for a shift in the approach of the current policies regarding the reduction of HEC in the Netherlands-in which energy efficiency of buildings is the keystone of introduced incentives and regulations (see Table 1). Policies need to break through the narrow perspective of building energy efficiency and take a more multidimensional approach. This is eminently necessary in order to properly adapt to ongoing trends in the Netherlands: the projected changes in household type towards smaller and more aged households-see population projections by the CBS (2011); the planned construction of half a million new dwellings in the Randstad region which will transform morphology of the cities - see the Randstad structural vision for 2040 (Rijksoverheid 2008); the expected change of climate in terms of temperature, wind speed, precipitation, solar radiation and cloudinesssee the climate scenarios by the KNMI (2015); the growing concerns about the urban heat island effect in Dutch urban environments and its effects on the urban microclimate-see, e.g. the study on urban heat islands in Amsterdam and Rotterdam (van der Hoeven and Wandl 2015a, b). Energy polices should not pass all these trends unnoticed. Household energy consumption within dwellings is not just about dwellings; policies shouldn't be either.

Acknowledgements This study is part of the DCSMART project founded in the framework of the joint programming initiative ERA-Net Smart Grids Plus, with support from the European Union's Horizon 2020 research and innovation program.

\section{Compliance with ethical standards}

Ethical standard Authors wish to declare that they have complied with all the ethical standards as it is required by journal of GeoJournal.

Conflict of interest Authors have no conflict of interest to declare.

Open Access This article is distributed under the terms of the Creative Commons Attribution 4.0 International License (http:// creativecommons.org/licenses/by/4.0/), which permits unrestricted use, distribution, and reproduction in any medium, provided you give appropriate credit to the original author(s) and the source, provide a link to the Creative Commons license, and indicate if changes were made.

\section{References}

Abrahamse, W., \& Steg, L. (2009). How do socio-demographic and psychological factors relate to households' direct and indirect energy use and savings? Journal of Economic Psychology, 30(5), 711-720.

Azevedo, J. A., Chapman, L., \& Muller, C. L. (2016). Urban heat and residential electricity consumption: A preliminary study. Applied Geography, 70, 59-67. https://doi.org/10. 1016/j.apgeog.2016.03.002

Barr, S., Gilg, A. W., \& Ford, N. (2005). The household energy gap: Examining the divide between habitual-and purchaserelated conservation behaviours. Energy Policy, 33(11), 1425-1444.

Belaï, F. (2016). Understanding the spectrum of domestic energy consumption: Empirical evidence from France. Energy Policy, 92(C), 220-233. https://doi.org/10.1016/j. eneco.2016.05.006

Bouzarovski, S., \& Simcock, N. (2017). Spatializing energy justice. Energy Policy, 107(C), 640-648. https://doi.org/ 10.1016/j.enpol.2017.03.064

Brunsdon, C., Fotheringham, A. S., \& Charlton, M. E. (1996). Geographically weighted regression: A method for exploring spatial nonstationarity. Geographical Analysis, 28(4), 281-298.

CBS. (2011). A million household more 2045. https://www.cbs. nl/en-gb/news/2011/14/a-million-households-more-by2045. Accessed Mar 10, 2017.

Centraal Bureau voor de Statistiek (2013). Wijk-en buurtkaart 2014. https://www.cbs.n1/nl-nl/dossier/nederland-regionaal/ geografische\%20data/wijk-en-buurtkaart-2014. Accessed Mar 08, 2018.

Druckman, A., \& Jackson, T. (2008). Household energy consumption in the UK: A highly geographically and socioeconomically disaggregated model. Energy Policy, 36(8), 3177-3192.

Esri Netherlands (2016). 3D BAG. http://www.esri.nl/nl-NL/ news/nieuws/sectoren/nieuw-in-arcgis-voor-leefomgeving. Accessed Mar 09, 2017.

European Environment Agency. (2016). https://www.eea. europa.eu/data-and-maps/data/clc-2012-raster. Accessed Mar 08, 2018. 
Eurostat. (2015). Half-yearly electricity and gas prices, second half of year 2012-14 (EUR per kWh). http://ec.europa.eu/ eurostat/statistics-explained/index.php?title=File:Half-yearly_ electricity_and_gas_prices,_second_half_of_year,_2012\% E2\%80\%9314_(EUR_per_kWh)_YB15.png\&oldid=238282. Accessed Mar 08, 2018.

Eurostat. (2018). http://ec.europa.eu/eurostat/statistics-explained/ index.php/Energy_consumption_in_households. Accessed Jan 29, 2018.

Ewing, R., \& Rong, F. (2008). The impact of urban form on US residential energy use. Housing Policy Debate, 19(1), $1-30$.

Figueroa, L. L. L., Lim, S., \& Lee, J. (2018). Modelling the effect of deprived physical urban environments on academic performance in the Philippines. GeoJournal, 83(1), 13-30.

Fotheringham, A. S., Brunsdon, C., \& Charlton, M. (2003). Geographically weighted regression (pp. 159-183). West Atrium: Wiley.

Fotheringham, A. S., Charlton, M., \& Brunsdon, C. (1996). The geography of parameter space: An investigation into spatial non-stationarity. International Journal of Geographic Information Systems, 10(5), 605-627. https://doi.org/10. 1080/026937996137909

Geniaux, G., \& Napoléone, C. (2008). Semi-parametric tools for spatial hedonic models: An introduction to mixed geographically weighted regression and geoadditive models. In: Baranzini, A., Ramirez, J., Schaerer, C., \& Thalmann, P. (Eds.), Hedonic Methods in Housing Markets (pp. 101-127). New York, NY: Springer.

Heinonen, J., Jalas, M., Juntunen, J. K., Ala-Mantila, S., \& Junnila, S. (2013). Situated lifestyles: I. How lifestyles change along with the level of urbanization and what the greenhouse gas implications are-A study of Finland. Environmental Research Letters, 8(2), 025003.

Isaac, M., \& Van Vuuren, D. P. (2009). Modeling global residential sector energy demand for heating and air conditioning in the context of climate change. Energy Policy, 37(2), 507-521.

Joyeux, R., \& Ripple, R. D. (2007). Household energy consumption versus income and relative standard of living: A panel approach. Energy Policy, 35(1), 50-60.

Kaza, N. (2010). Understanding the spectrum of residential energy consumption: A quantile regression approach. Energy Policy, 38(11), 6574-6585.

Kim, J. P. (2013). Variation in the accuracy of thermal remote sensing. International Journal of Remote Sensing, 34(2), 729-750.

KNMI. (2015). KNMI' 14 Climate scenarios for the Netherlands. http://www.climatescenarios.nl/. Accessed Aug 03, 2018.

KNMI. (2018). http://www.sciamachy-validation.org/climatology/ daily_data/selection.cgi. Accessed Mar 08, 2018.

Kowsari, R., \& Zerriffi, H. (2011). Three dimensional energy profile: A conceptual framework for assessing household energy use. Energy Policy, 39(12), 7505-7517.

Lee, S., \& Lee, B. (2014). The influence of urban form on GHG emissions in the US household sector. Energy Policy, 68(C), 534-549. https://doi.org/10.1016/j.enpol.2014.01.024

Li, J., Huang, X., Yang, H., Chuai, X., Li, Y., Qu, J., et al. (2016). Situation and determinants of household carbon emissions in Northwest China. Habitat International, 51, 178-187. https://doi.org/10.1016/j.habitatint.2015.10.024

Majcen, D., Itard, L. C. M., \& Visscher, H. (2013). Theoretical vs. actual energy consumption of labelled dwellings in the Netherlands: Discrepancies and policy implications. Energy Policy, 54(C), 125-136. https://doi.org/10.1016/j. enpol.2012.11.008

Mashhoodi, B. (2018). Spatial dynamics of household energy consumption and local drivers in Randstad, Netherlands. Applied Geography, 91, 123-130. https://doi.org/10.1016/ j.apgeog.2018.01.003

Mashhoodi, B., \& van Timmeren, A. (2018). Local determinants of household gas and electricity consumption in Randstad region, Netherlands: Application of geographically weighted regression. Spatial Information Research, 26(6), 607-618.

Ministry of Economic Affairs. (2014). Third National Energy Effciency Action Plan for the Netherlands. Submitted to European Commission: https://ec.europa.eu/energy/sites/ener/files/ documents/NEEAP_2014_nl-en.pdf238282/. Accessed May 08, 2018.

Nakaya, T., Fotheringham, A. S., Charlton, M., \& Brunsdon, C. (2009). Semiparametric geographically weighted generalised linear modelling in GWR 4.0. In B. Lees \& S. Laffan (Eds.), 10th International conference on geocomputation. Sydney, Australia. Accessed 10 Dec 2018.

O'neill, B. C., \& Chen, B. S. (2002). Demographic determinants of household energy use in the United States. Population and Development Review, 28, 53-88.

Pachauri, S., \& Jiang, L. (2008). The household energy transition in India and China. Energy Policy, 36(11), 4022-4035.

Porse, E., Derenski, J., Gustafson, H., Elizabeth, Z., \& Pincetl, S. (2016). Structural, geographic, and social factors in urban building energy use: Analysis of aggregated accountlevel consumption data in a megacity. Energy Policy, 96, 179-192. https://doi.org/10.1016/j.enpol.2016.06.002

Reinders, A. H., Vringer, K., \& Blok, K. (2003). The direct and indirect energy requirement of households in the European Union. Energy Policy, 31(2), 139-153.

Rijksoverheid. (2008). https://www.rijksoverheid.nl/documenten/ brochures/2008/09/01/structuurvisie-randstad-2040-in-hetkort. Accessed Mar 08, 2018.

Robinson, C., Bouzarovski, S., \& Lindley, S. (2018). Underrepresenting neighbourhood vulnerabilities? The measurement of fuel poverty in England. Environment and Planning A: Economy and Space, p.0308518X18764121.

Sanaieian, H., Tenpierik, M., van den Linden, K., Seraj, F. M., \& Shemrani, S. M. M. (2014). Review of the impact of urban block form on thermal performance, solar access and ventilation. Renewable and Sustainable Energy Reviews, 38(C), 551-560. https://doi.org/10.1016/j.rser.2014.06.007

Shoff, C., Yang, T. C., \& Matthews, S. A. (2012). What has geography got to do with it? Using GWR to explore placespecific associations with prenatal care utilization. GeoJournal, 77(3), 331-341.

Silva, J., Ribeiro, C., \& Guedes, R. (2007). Roughness length classification of Corine Land Cover classes. In Proceedings of the European Wind Energy Conference, Milan, Italy (Vol. 710, p. 110).

Sluiter, R. (2012). Interpolation methods for the climate atlas. KNMI technical rapport TR-335, Royal Netherlands Meteorological Institute, De Bilt (pp. 1-71). 
Stathopoulou, M., \& Cartalis, C. (2007). Daytime urban heat islands from Landsat ETM + and Corine land cover data: An application to major cities in Greece. Solar Energy, 81(3), 358-368.

Steemers, K., \& Yun, G. Y. (2009). Household energy consumption: A study of the role of occupants. Building Research \& Information, 37(5-6), 625-637.

Stein, R. E., Conley, J. F., \& Davis, C. (2016). The differential impact of physical disorder and collective efficacy: A geographically weighted regression on violent crime. GeoJournal, 81(3), 351-365.

Stepek, A., \& Wijnant, I. L. (2011). Interpolating wind speed normals from the sparse Dutch network to a high resolution grid using local roughness from land use maps. Koninklijk Nederlands Meteorologisch Instituut, Technical Report TR-321.

Sultana, S., Pourebrahim, N., \& Kim, H. (2018). Household Energy Expenditures in North Carolina: A Geographically Weighted Regression Approach. Sustainability, 10(5), 1511 .

USGS. (2018a). https://landsat.usgs.gov/using-usgs-landsat-8product. Accessed Mar 08, 2018.

USGS. (2018b). https://earthexplorer.usgs.gov/. Accessed Mar 08, 2018.

van der Hoeven, F. D., \& Wandl, A. (2015a). Amsterwarm: Mapping the landuse, health and energy-efficiency implications of the Amsterdam urban heat island. Building Services Engineering Research and Technology, 36(1), $67-88$.

Van der Hoeven, F. D., \& Wandl, A. (2015b). Hotterdam: Hoe ruimte Rotterdam warmer maakt, hoe dat van invloed is op de gezondheid van inwoners, en wat er aan te doen is. TUDelft Bouwkunde.

Van Moeseke, G., Gratia, E., Reiter, S., \& De Herde, A. (2005). Wind pressure distribution influence on natural ventilation for different incidences and environment densities. Energy and Buildings, 37(8), 878-889.

Vaziri, M., Acheampong, M., Downs, J., \& Majid, M. R. (2018). Poverty as a function of space: Understanding the spatial configuration of poverty in Malaysia for Sustainable Development Goal number one. GeoJournal. https://doi. org/10.1007/s10708-018-9926-8.

Wang, Q. (2014). Effects of urbanisation on energy consumption in China. Energy Policy, 65(C), 332-339. https://doi. org/10.1016/j.enpol.2013.10.005

Weber, C., \& Perrels, A. (2000). Modelling lifestyle effects on energy demand and related emissions. Energy Policy, 28(8), 549-566.

Wiedenhofer, D., Lenzen, M., \& Steinberger, J. K. (2013). Energy requirements of consumption: Urban form, climatic and socio-economic factors, rebounds and their policy implications. Energy Policy, 63(C), 696-707. https://doi.org/10.1016/j.enpol.2013.07.035

$\mathrm{Yu}$, D. (2014). Understanding regional development mechanisms in Greater Beijing Area, China, 1995-2001, from a spatial-temporal perspective. GeoJournal, 79(2), 195-207.

$\mathrm{Yu}, \mathrm{H}$. (2012). The influential factors of China's regional energy intensity and its spatial linkages: 1988-2007. Energy Policy, 45, 583-593. https://doi.org/10.1016/j.enpol.2012. 03.009

Yu, B., Zhang, J., \& Fujiwara, A. (2013). A household time-use and energy-consumption model with multiple behavioral interactions and zero consumption. Environment and Planning B: Planning and Design, 40(2), 330-349.

Zeng, C., Yang, L., Zhu, A. X., Rossiter, D. G., Liu, J., Liu, J., et al. (2016). Mapping soil organic matter concentration at different scales using a mixed geographically weighted regression method. Geoderma, 281, 69-82. https://doi.org/ 10.1016/j.geoderma.2016.06.033

Zhang, H., \& Song, W. (2014). Addressing issues of spatial spillover effects and non-stationarity in analysis of residential burglary crime. GeoJournal, 79(1), 89-102.

Publisher's Note Springer Nature remains neutral with regard to jurisdictional claims in published maps and institutional affiliations. 